\title{
MORE ON $L^{p}$-INTEGRABILITY
}

\section{Yi ZHAO AND SONGPING ZHOU}

Abstract. In this paper, we give a further generalization to $L^{p}$-integrability of trigonometric series connecting with derivatives of the sum-functions.

Mathematics subject classification (2010): 42A25, 42A50.

Keywords and phrases: Integrability, mean value bounded variation, monotonicity.

\section{REFERENCES}

[1] R. A. Askey AND S. WAINGER, Integrability theorems for Fourier series, Duke Math. J., 33 (1966), 223-228.

[2] JR. P. R. BoAs, Integrability Theorems for Trigonometric Transforms, Springer, Berlin-Heidelberg, 1967.

[3] R. J. Le AND S. P. ZHOU, A remark on "two-sided" monotonicity condition: an application to $L^{p}$ convergence, Acta Math. Hungar. 113 (2006), 159-169.

[4] L. LeIndLer, Generalization of inequalities of Hardy and Littlewood, Acta Sci. Math. (Szeged) 31 (1970), 279-285.

[5] L. LeINDLER, Relations among Fourier series and sum-functions, Acta Math. Hungar. 104 (2004), 171-183.

[6] D. S. Yu, P. Zhou AND S. P. ZHOU, On $L^{p}$ integrability and convergence of trigonometric series, Studia Math. 182 (2007), 215-226.

[7] S. P. Zhou, Monotonicity Condition of Trigonometric Series: Development and Application, Science Press, Beijing, 2012, in Chinese.

[8] S. P. ZHOU, P. ZHOU AND D. S. YU, Ultimate generalization to monotonicity for uniform convergence of trigonometric series, Science China Math. 53 (2010), 1853-1862/available: arXiv: math.CA/0611805 v1 27 Nov 2006.

[9] A. Zygmund, Trigonometric Series, Cambridge University Press, Cambridge, 1977. 